ISAHP Article: Desai,Iyer /An Integrated Approach for Management of Global Risks To Be Submitted to the International Symposium of the Analytic Hierarchy Process 2014, Washington D.C., U.S.A.

\title{
AN INTEGRATED APPROACH FOR MANAGEMENT OF GLOBAL RISKS
}

\author{
Pawan Desai \\ MitKat Ventures (P) Ltd, \\ Mumbai, INDIA \\ E-mail: pawan.desai@mitkatadvisory.com \\ Karthikeyan Iyer \\ Verchaska Infotech (P) Ltd, \\ Mumbai, INDIA \\ E-mail: iamkart@gmail.com
}

\begin{abstract}
Until recently, businesses across the world have grown locally before venturing on a global scale. As a result, current risk management approaches are optimized to manage localized risks i.e. internal or in the immediate business environment. Risk managers are also attuned to these practices. Risk related decisions are taken by a small set of business leaders.

However, in an increasingly networked world, businesses serve global customers using global infrastructure, resources and knowledge. Local events are having increasingly global impact. Decision makers are globally distributed. Without the ability to construct an effective big picture of risk, most risk managers try to manage risks locally and hope that super-system risks will manage themselves. Often, local risks are simplistically extrapolated or magnified with sub-optimal results.
\end{abstract}

There are proven frameworks in prior art that address elements of the problem. Scenario Writing helps to explore how a business, its ecosystem and risks therein are expected to evolve globally. The Nine Windows approach helps organize risks using a scalable space-time representation. The Analytic Hierarchy Process allows experts to organize global risks in a hierarchy and build consensus on the relative impact of those risks at local and global scales.

This paper describes a framework that combines Scenario Writing, Nine Windows and The Analytic Hierarchy Process to help businesses manage global risks. The paper also presents a case to study to illustrate the benefits of this framework over conventional localized risk management approaches.

Keywords: Nine Windows, Global Risks, AHP. 